\title{
La reivindicación cultural e identitaria a través de la autotraducción: el caso de la poesía autotraducida de Xuan Bello del asturiano al español
}

\author{
por Beatriz Flores Silva
}

\section{INTRODUCCIÓN}

\begin{abstract}
T A DIVERsidad lingüística y cultural es una realidad en España. Además de utilizar la lengua oficial del Estado español, en otras Comunidades Autónomas ${ }^{1}$ se hablan otras lenguas autóctonas que también contribuyen a enriquecer el todo que compone la cultura española. Teniendo en cuenta este hecho, se debe reconocer que la producción literaria española se nutre también de las obras escritas por autores bilingües en lenguas periféricas ${ }^{2}$. No obstante, en ocasiones, tales composiciones no se dan a conocer en todo el sistema peninsular. Para evitar quedar en una posición exclusivamente minoritaria, los autores que se expresan en lenguas minoritarias
\end{abstract}

' Las Comunidades Autónomas en las que se habla otra lengua peninsular, además del español, son las siguientes: Galicia, País Vasco, Cataluña, Asturias, Comunidad Valenciana, Islas Baleares y Aragón. No obstante, cabe añadir que en determinadas zonas de Castilla y León y Cantabria se recurre a utilizar alguna variante del asturiano; mientras que, por ejemplo, en ciertas áreas de Navarra se habla también euskera.

2 En este sentido, se entiende por «lengua periférica» cualquier lengua diferente a la central o dominante, esto es, el español. 
deciden traducir por sí mismos sus propias obras al español con el fin de lograr una mayor proyección y encontrar así, un hueco en el sistema español e incluso, en otros sistemas dominantes extranjeros.

Algunos de estos autores también recurren a la autotraducción para dar voz a sus reivindicaciones socioculturales más allá del sistema minoritario. Además, para muchos, el hecho de traducir sus propios textos constituye un ejercicio de introspección que conduce al encuentro con la identidad tanto individual como colectiva, es decir, con la identidad del núcleo regional con el que guardan un sentimiento de pertenencia. Así, estos pueden llegar a contemplar la lengua dominante como un instrumento que permite trasladar sus pensamientos y sus demandas para que así, resuenen en el espacio dominado por el otro, una realidad de la que también forman parte.

Hoy en día, la prolífica actividad de muchos autores-traductores peninsulares ha conseguido darse a conocer en otros círculos literarios. Además, sus resultados han despertado el interés de los Estudios de Traducción. Sin embargo, hay voces que, pese a haber encontrado una posición en el sistema dominante, merecen ser escuchadas con más atención.

\section{LA AUTOTRADUCCIÓN EN EL SISTEMA PENINSULAR}

Siempre han existido autores que han preferido asumir la responsabilidad de traducir sus propias obras antes de relegar esta tarea en manos ajenas. Autores de referencia en la literatura universal, como Beckett, Joyce o Nabokov, decidieron seguir el camino de la autotraducción que, de acuerdo con la definición de Popovič (1976, pág. 19), se trata de «the translation of an original work into another language by the autor himself»?

3 «La traducción que el propio autor hace de una obra original a otra lengua» (traducción mía). 
Por su doble riqueza tanto lingüística como cultural, España se dibuja como un lugar ideal para el cultivo de la autotraducción en el ámbito literario. Un importante número de escritores bilingües que pueden comunicarse y escribir en dos lenguas peninsulares -en una minoritaria y en español- deciden autotraducirse, lo que también les convierte en «traductores sui generis por su conocimiento de la obra original» (Tanqueiro, 1999, pág. 22). Un ejemplo de este tipo particular de traductores son los poetas asturianos promotores del movimiento literario del Surdimientu, como Xuan Bello, que aprovechan su aventajado bilingüismo y biculturalidad para traducir sus propias composiciones del asturiano al español. De este modo, el autor-traductor se convierte en el creador de dos textos que se complementan "como si fueran el anverso y el reverso de la misma moneda, puesto que son inseparables e intercambiables» (Dasilva, 20I5, pág. II7).

La gran mayoría de estos autores recurren a la autotraducción para alcanzar, principalmente, un doble objetivo. Por un lado, para difundir sus obras escritas en su lengua minoritaria en el espacio cultural y lingüístico central. Por otro lado, los textos ya traducidos al español le abrirán una vía que les facilitará su posterior recepción en otros sistemas extranjeros, puesto que todavía resulta más frecuente, y en cierto modo más sencillo, traducir del español a otra lengua extranjera mayoritaria. De esta manera, lejos de invisibilizar la esencia de la lengua y la cultura minoritarias, lo que se pretende mediante la traducción del español a otra lengua es, precisamente, hacer que dicho sistema peninsular minoritario se conozca en otras realidades socioculturales dominantes. Por tanto, rescatando las palabras de Carbonell (1997, pág. 29), la traducción debe considerarse "como un paradigma de contacto cultural», como un medio que guía hacia el entendimiento e impulsa el descubrimiento de otros.

Además, cabe añadir que gran parte de los autores que se autotraducen, lo hacen también motivados por diferentes razones. No se puede 
obviar, por tanto, que algunos encuentran en la autotraducción una aliada en la que se apoyan, por ejemplo, para obtener beneficios de carácter económico, abrirse paso en otros mercados editoriales o acumular mayor "capital simbólico» (Bourdieu, 1980). No obstante, también hay autores que contemplan la autotraducción como una oportunidad para poner de manifiesto sus reivindicaciones de carácter social e ideológico e, igualmente, para definir su identidad tanto lingüística como cultural dentro del complejo escenario peninsular. Por tanto, como bien argumenta Grutman (apud Dasilva, 20I5, pág. 177), «l'autotraduzione non è un fenómeno isolato ma forma parte di uno svolgimento socioculturale ${ }^{4}$.

No hay que olvidar que en España existe una situación de diglosia, puesto que el español es la lengua oficial de todo el Estado, mientras que el resto de lenguas peninsulares ocupan una posición periférica. Sin embargo, el catalán, el gallego y el vasco gozan de un estatus de cooficialidad y cuentan con una importante aceptación no solo en sus respectivas regiones de origen, sino también en determinados sectores de la sociedad española. Generalmente, se valora la coexistencia de estas lenguas y la promoción de su uso en distintos ámbitos como un hecho positivo que alimenta la cultura nacional. Sin embargo, existen otras lenguas minoritarias que quedan relegadas a un plano secundario, lo que hace que, de cierta manera, todavía se encuentren alejadas de obtener un amplio prestigio dentro de la sociedad española, siendo este el caso del asturiano. Aun así, los defensores del uso y promoción de la lengua y la cultura asturianas se esfuerzan por buscar mecanismos para integrarlas no solo en su propia comunidad de origen, sino también en toda la dimensión peninsular e, igualmente, para exigir el reconocimiento que realmente merecen.

«La autotraducción no es un fenómeno aislado, sino que forma parte de un movimiento sociocultural» (traducción mía). 
Por esta razón, para los autores que escriben desde sistemas minoritarios, unidos por el sentimiento de pertenencia a una misma cultura, la autotraducción se ha convertido en un instrumento que permite dar voz a su particular manera de transmitir su reivindicación sociocultural. Igualmente, es frecuente que algunos autores vean también en la autotraducción una ocasión para definir su propia identidad cultural, vinculada a dos espacios, puesto que le otorga la oportunidad de «expresar en una lengua común la representación de la propia pertenencia, la herencia de una experiencia íntima con la lengua y la tradición dominada» (Hernández, 20IO, pág. II4). Por tanto, consideramos que Xuan Bello, como otros tantos escritores que se expresan en una lengua minoritaria, halla en la autotraducción una cómplice que le da las claves para hacer visibles no solo sus más íntimos pensamientos, sino también aquellos valores culturales y lingüísticos que caracterizan a su región, esto es, Asturias.

\section{La poesía de Xuan Bello}

Desde el principio, Xuan Bello recurre al asturiano para escribir su poesía. Esta lengua dota a sus versos de una musicalidad suave que puede llegar a despertar en el lector un sentimiento de nostalgia, pese a que parte de la sociedad asturiana considere que se trata de una lengua arcaica, en declive. Aun así, es la lengua en la que los poetas asturianos del Surdimientu escriben sus composiciones. De esta manera, también muestran su compromiso por realzar un elemento clave que conforma la identidad colectiva asturiana.

Gran parte de los poemas y relatos que Xuan Bello recoge en sus obras -destacándose Los nombres de la tierra (1991), Hestoria Universal de Paniceiros (2003), Ambos mundos (2010)- reviven los recuerdos de un tiempo irrecuperable que se fotografían en un ambiente alejado de la volátil urbe y su incesante ritmo de vida. Así, contextualiza su discurso lírico en el mundo rural donde cobra un especial protagonismo la 
naturaleza. El campo representa aquel territorio prácticamente abandonado en nuestro presente donde la cultura asturiana hunde sus raíces olvidadas, donde todavía perviven los mitos y los símbolos autóctonos con los que se identifica la comunidad de esta región, por ejemplo, la casa, el campo, la patria o el pueblo, entre otros muchos elementos. El poeta escribe poemas que recrean un Paniceiros que para él constituye el centro del universo. Un Paniceiros dibujado como un lugar mitificado en el que confluyen las emociones por recuperar las tradiciones y las señas de identidad que unen a sus paisanos. Igualmente, a través de sus versos manifiesta el deseo por volver a la vida típica asturiana en el campo, enterrada ya por el inevitable paso del tiempo.

Además, los poemas de Xuan Bello desprenden notas intimistas, como el anhelo por encontrarse de nuevo en la casa familiar, la añoranza del pasado perdido, la memoria de la tierna niñez campesina, las conmociones de la juventud, las inquietudes existenciales y el exilio interior, a lo que se suman las intenciones por rescatar la esencia de la cultura y la lengua de Asturias. Todas estas emociones crean lo que este autor asturiano denomina el sentimientu de la tierra -o «sentimiento de la tierra»- y que define de la siguiente manera: «esi sentimientu de búsqueda, de desosiegu y tresiegu interior, que ta afaláu por esa llave filosófica del Destín que ye la señaldá, la singularidá de los asturianos» (apud Sánchez, 2006, pág. II). Este "sentimiento de la tierra» inunda los versos recogidos en la antología bilingüe La vida perdida (1999) y ha logrado convertirse en un paradigma poético seguido por otros poetas asturianos contemporáneos. Un sentimiento de (des)encuentro con los orígenes, una mirada hacia el mundo que todavía late en los resquicios de la memoria, que no solo intenta transmitir a sus lectores en lengua asturiana, sino también en español. Una tarea que también ponen en práctica otros poetas asturianos, como Berta Piñán o Xuan Santori, que se autotraducen al español para trasladar sus versos más allá de su frontera regional, para darlos a conocer en el espacio literario dominante. 


\section{Xuan Bello como autotraductor}

El poeta asturiano Xuan Bello, perteneciente a la segunda generación de poetas del Surdimentu, otorga voz a sus versos en asturiano y los traduce al español. Para este poeta, el asturiano es el medio de expresión desde el que parte para materializar en sus composiciones las ideas y las imágenes de tiempos pasados que perviven en su memoria. Posteriormente, vuelve a dar vida a esas palabras en una lengua tan suya como la asturiana, es decir, en español. En una entrevista que ofreció a la revista Biblioasturias, Xuan Bello (20II, pág. 22) introduce la siguiente aclaración sobre su manera de escribir y la dirección que toma en el proceso de autotraducción, de la cual parece que nunca se ha desviado hasta el momento:

Mi forma de trabajar es esta: escribo en asturiano, me traduzco al castellano, vuelvo a traducirme al asturiano, me veo impelido a ponerme otra vez en castellano. La rosa no es rosa por ser rosa apenas: lo es porque florece cada oportunidad que tiene de florecer.

Por tanto, el poeta concibe la autotraducción como una oportunidad para volver a reflexionar sobre aquello que ya ha escrito y trasladar sus pensamientos a otra lengua -próxima, pero al mismo tiempo distanciada- que también configura una parte de sí mismo. En ocasiones, también puede recurrir a la autotraducción con el fin de mejorar estéticamente el poema u observar detenidamente ciertos matices que, quizás, habían pasado desapercibidos. No obstante, para el poeta asturiano, la autotraducción no es únicamente un ejercicio de autocorrección o de ayuda para trabajar en el desarrollo de su capacidad de expresión o explotar su creatividad.

Así, tras la libre decisión de escribir poesía en una lengua minoritaria $y$, posteriormente, traducirse para proyectarse en el espacio peninsular, se esconde una clara intención de reivindicación lingüística y sociocultural. Además, la autotraducción no debe entenderse solamente como 
un instrumento para exaltar las demandas de carácter sociocultural, sino que también "puede articularse como la búsqueda de la identidad propia de un individuo» (Castillo, 2006, págs. 58-59) que se sitúa en un espacio intermedio entre dos sistemas socioculturales. Por tanto, la autotraducción conduce hacia la definición de «un'identità duplice, di un'identità in between'» (Cocco, 2009, pág. III). De esta manera, deducimos que Xuan Bello, a través de la autotraducción, no pretende solamente exaltar la lengua y cultura asturianas, sino también definir su propia identidad.

\section{LA AUTOTRADUCCIÓN COMO MEDIO DE REIVINDICACIÓN}

DE LA LENGUA Y LA CULTURA ASTURIANAS

La poesía podría trazarse como un potente caudal de palabras, sonidos e imágenes sugerentes por el que fluyen los sentimientos y las visiones de un autor. Del mismo modo, hay poetas que deciden indagar más allá de sus propias emociones y, a través de sus composiciones, tratan de construir una representación de la realidad social y cultural de la que participan. En un sentido amplio, consideramos que la literatura abre ventanas que nos acercan al conocimiento de distintas visiones del mundo, a la escucha de las experiencias de los Otros. De esta manera, la literatura se convierte en un medio de reafirmación cultural. Para reforzar este argumento, se destacan las palabras de la Doctora en Antropología, García Del Villar (2005, pág. 48), que dicen así:

La literatura, aún asentada sobre las bases del imaginario, nos ofrece información que de otro modo nos sería imposible conocer, tanto de hechos pasados, referentes históricos o míticos, como de plasmaciones de valores y costumbres, imágenes y estereotipos, referentes a una amplia gama de ámbitos sociales.

\footnotetext{
5 «Una identidad doble, de una identidad in between» (traducción mía).
} 
Sin abandonar la emotividad y la subjetividad, la poesía de Xuan Bello invita a los lectores a aproximarse al sistema sociocultural y lingüístico de Asturias. A lo largo de sus versos, este poeta dibuja los límites de un mundo único que recrea en esa tierra que le vio crecer y donde perviven sus recuerdos. Además, en sus poemas rescata elementos y símbolos que le ayudan a definir la singularidad de la cultura de su región. Para alcanzar este último propósito, Xuan Bello recurre a un elemento fundamental donde se asienta uno de los pilares más significativos de cualquier cultura; un componente que todo aquel que se aventure a leer sus composiciones originales puede apreciar a primera vista: la lengua asturiana.

Xuan Bello redacta sus primeros poemas en la lengua minoritaria con la que creció. Es posible que prefiera dar vida a sus palabras en esta lengua por razones afectivas y, por ende, personales. Siguiendo esta línea, suponemos que para este poeta la lengua asturiana es el nexo que conecta su inmediata memoria del pasado con su yo del presente. Es la única capaz de evocar aquellas imborrables experiencias de su niñez y juventud, etapas de la vida que solo saben susurrar en asturiano. Además, para este poeta, esta lengua es un fuerte lazo que le une con esa dimensión singular que constituye «la patria ${ }^{6} »$, esa particular representación de su propio universo. Por tanto, entendemos que el asturiano permite a Xuan Bello «expresarse de una forma más cercana, escribir historias de su pueblo para su pueblo» (Ghignoli y Hernández Rodríguez, 20I5 pág. 138) que luego serán transmitidas al sistema mayoritario.

No obstante, el hecho de escribir en una lengua minoritaria puede ser interpretado también como un acto de reivindicación tanto cultural como lingüística, una hipótesis que en este caso concreto cobra especial sentido. Recordemos que el asturiano es una lengua que no solo se si-

\footnotetext{
${ }^{6}$ En algunos de los poemas que se incluyen en La vida perdida (1999), Xuan Bello habla de un lugar que él mismo denomina "patria».
} 
túa en una posición periférica dentro del complejo sistema peninsular, sino que también en su sistema de origen no ha logrado todavía ganar ese reconocimiento que lleva persiguiendo hace tiempo. Gran parte de los escritores que escriben en lengua asturiana dejan entrever su compromiso por elevarla a la categoría de lengua respetada y legítima, al menos, en el corazón de su región. Tales escritores, como Xuan Bello, son afines al movimiento que promociona la recuperación de la lengua, la literatura y la cultura de Asturias, esto es, el Surdimientu. Por tanto, escribir en la lengua autóctona de esta comunidad es el primer paso para materializar esta reivindicación y nutrir la literatura escrita en asturiano. Sin embargo, para que dicha reivindicación realmente adquiera fuerza, es necesario extenderla hacia otros espacios. Por esta razón, algunos autores asturianos han decidido otorgar voz a estas demandas a través de sus composiciones. Pero para que estas se escuchen en todo el sistema peninsular, han recurrido a la autotraducción ${ }^{7}$.

Los autores-traductores asturianos encuentran en la lengua dominante un apoyo para difundir sus mensajes. Por tanto, esta no siempre trata de invisibilizar la presencia de la lengua minoritaria en el texto traducido, sino todo lo contrario. Así, el idioma que goza de prestigio llega a convertirse en un vehículo que otorga voz a la lengua y a la cultura asturianas para que puedan darse a conocer en todos los rincones del sistema peninsular. Esa lengua mayoritaria puede facilitar la proyección tanto de la lengua autóctona como de la cultura de Asturias en otros sistemas extranjeros. Pues no olvidemos que una de las finalidades de la autotraducción consiste en mediar entre dos o más culturas y acercar realidades.

7 Los trabajos de autotraducción del asturiano al español encontraron su espacio hace, relativamente, poco tiempo. Así que, como apunta Santoyo (2015, pág. 5I): «el bable, llingua asturiana o asturianu es un recién llegado al mundo de la autotraducción, sin duda porque también la literatura en esa lengua es muy reciente, con una historia que no va más allá de cincuenta años». 


\section{LA BÚSQUEDA DE LA IDENTIDAD A TRAVÉS}

DE LA AUTOTRADUCCIÓN

La autotraducción puede ser vista también como la llave que abre la puerta hacia el autoconocimiento. De acuerdo con Castillo (2006, pág. 66), los autores-traductores "comparten la experiencia de vivir "entre dos mundos", por lo que pueden servirse de la traducción para buscar su propia identidad cultural».

Además, la autotraducción se convierte en un ejercicio de introspección. Al releer y reescribir su propio texto en otra lengua, el autor tiene la oportunidad de reinterpretar los pensamientos y los sentimientos que ha materializado a través de las palabras y de volver a sumergirse en su mundo interior desde un espacio cultural y lingüístico distinto, pero que conoce desde cerca. Cuando un autor traduce sus propios textos, no se limita simplemente a trasladar a otra lengua las palabras, los elementos culturales u otros matices que abundan en sus textos, con el fin de que estos sean leídos en otro sistema cultural. En este proceso, dicho autor consigue abrir una vía que le guía hacia el (re)descubrimiento de sí mismo, hacia el intento por determinar quién es y dónde se ubica realmente. Según Vega (2002, pág. 50), la actividad autotraductora puede implicar «una fecunda reflexión sobre las diferentes identidades que conviven en el seno de un escritor bilingüe». Autotraducirse pues, supone emprender la búsqueda de la propia identidad que, en definitiva, queda configurada por los dos sistemas culturales a los que simultáneamente uno pertenece. Una identidad que constituye un punto de encuentro -o tal vez, de desencuentro- entre dos visiones diferentes del mundo. Por tanto, Xuan Bello, a través de la práctica traductora, no solo trata de definir la identidad cultural de Asturias, sino también de hallar sus propias señas de identidad. 
Un autor-traductor es un individuo que reúne en sí mismo una doble identidad, por lo que además de bilingüe, se diferencia por ser bicultural. Esta particular identidad es producto de los sistemas culturales entre los que se encuentra y que, consecuentemente, determinan su comportamiento, su forma de contemplar el mundo y su razón de ser. Un auto-traductor es, por tanto, un sujeto que asume lo que Nowicki (2007, pág. 174) define como «la condition de l'homme contemporain, confronté simultanément à plusiers univers spirituels et culturels» ${ }^{8}$. Así, en una sola persona ya no habita un único yo, sino varios yoes.

El hecho de estar situado en un espacio intermedio tan singular hace que algunos autores no terminen de identificarse con ese «mismo»-desde donde sus palabras cobran vida-, pero tampoco con el «otro». Por esta razón, hay quienes no se sienten ni de un lugar ni de otro, sino que sienten que pertenecen a ambos a la vez. Aunque no todos llegan a determinar cuál es su identidad. Por tanto, algunos autores-traductores, como Xuan Bello, prefieren definirse a sí mismos como un «ser del mundo». En este sentido, destacamos una reflexión sobre la identidad que este poeta y traductor asturiano (20II, págs. 24-25) ofrece a la revista Biblioasturias, palabras que dicen así:

La suma final de un hombre, que ha asumido "X» identidades, es la identidad de ese hombre. Quiero decir: nadie nace con una identidad inmutable. [...] Vivir es sumar: ya habrá tiempo, que llegará, para que nos resten o nos dividan.

Además, continúa explicando lo siguiente (20II, pág. 25): «hasta ahora me he librado de ser uno solo a costa de los muchos que soy (y puedo ser). Soy de Paniceiros (Tineo): soy del mundo».

\footnotetext{
8 «La condición del hombre contemporáneo, enfrentado simultáneamente a distintos universos espirituales y culturales» (traducción mía).
} 


\section{La Vida perdida de Xuan Bello: ilustración de dos poemas AUTOTRADUCIDOS DEL ASTURIANO AL ESPAÑOL}

Llegados a este punto, en este apartado se introducen dos poemas de la antología bilingüe La vida perdida (1999) de Xuan Bello9 que tomamos como ejemplos para fundamentar la hipótesis que se ha ido desarrollando en líneas anteriores. Por un lado, se tratará de observar si la autotraducción se puede convertir en una aliada para transmitir las reivindicaciones de carácter sociocultural que defiende el poeta. Por otro lado, se valorará si este ejercicio supone una ayuda para que el autortraductor construya su propia identidad.

\section{El poema sobre Paniceiros}

En gran parte de sus poemas, Xuan Bello reflexiona sobre su sentimiento de pertenencia. Tras estos se esconden preguntas a las que el autor trata de dar respuesta con el fin de definir tanto su origen como su propia identidad. Preguntas que desprenden notas de carácter existencialista, por ejemplo: ¿a qué mundo pertenezco? ¿De dónde soy realmente? ¿Con qué o quiénes me identifico? Para un individuo que se sitúa en dos sistemas socioculturales localizados físicamente en un mismo terreno, de manera simultánea, resolver estas cuestiones desemboca en un complejo ejercicio de reflexión y diálogo interior.

Los vínculos que crea el autor con los distintos mundos que se levantan frente a él son diferentes. Es probable que desarrolle un sentimiento de pertenencia más fuerte hacia un sistema que a otro, un hecho que, en definitiva, encuentra su explicación en las propias circunstancias persona-

9 Cabe destacar que, al final de la antología La vida perdida, se indica que el autor contó con colaboradores para realizar las traducciones del asturiano al español. 
les de cada uno. Pero esto no implica que las señas del otro sistema cultural -que podrían denominarse como las señas hispánicas o peninsulares-, no tengan significado para el autor, puesto que constituyen también una parte inherente de su persona que aúna en sí múltiples identidades.

Por su origen asturiano, consideramos que Xuan Bello puede sentir una conexión más estrecha con ese mundo que le vio nacer. Sin embargo, las huellas del otro sistema no desaparecen, su esencia es imborrable, pues como el mismo poeta apunta (20II, pág. 24), «me he empeñado en ser asturiano, pero eso no invalida mi identidad hispánica, europea». Aun así, el autor prefiere no definirse ni de un espacio ni de otro. Aunque parece que sí logra encontrar una parte de sí mismo en Paniceiros, el lugar del que dice ser y al que dedica el siguiente poema que se incluye en La vida perdida (I999, págs. 50-5I):

Paniceiros

Conozco un país onde'l mundu llámase

Zarréu Grandiella Picu la Mouta Paniceiros

Un mundu que perdéu l'aldu los caminos

Xerusalén llevantao na palma la mano d'un nenu

Un mundu que yera luminosu esbeltu

Naciente y fonte y vocación de riu

Onde los homes callen y el silenciu ye renuncia

Onde escaecimos el ser Onde claudicamos

Un pais onde la casa cai Cai l'horru la ponte

el molín la ilesia l'home también cai

Onde la mirada yera pura cenciella

la xaceda que dexara la nube en cielu

Onde namás nos queda la memoria

corrompida de la infancia La nuesa soledá

L'abandonu de nueso

\section{Paniceiros}

Conozco un país donde el mundo se llama Zarréu Grandiella Picu la Mouta Paniceiros

Un mundo que perdió sus caminos

Jerusalén levantada en la palma de la mano de un niño

Un mundo que era alto luminoso esbelto

Naciente y fuente y vocación de río

Donde los hombres callan y el silencio es renuncia

Donde olvidamos el ser Donde claudicamos

Un país donde la casa cae Cae el hórreo el puente el molino la iglesia el hombre también cae

Donde la mirada era pura sencilla

la huella que había dejado la nube en el cielo

Donde tan sólo nos queda la memoria

corrompida de la infancia Nuestra soledad

El abandono nuestro 
Tanto el texto escrito en asturiano como el traducido al español, tratan de representar la imagen de un lugar que Xuan Bello define como «el mundo» que se sitúa en un país que dice conocer. Este país se relaciona directamente con la proyección de la cultura asturiana en decadencia, pues según Mori (2006, pág. 22):

La patria y el país, nesti tipu de poesía, designen un territoriu non definíu dende'l puntu de vista políticu que los autores identifiquen implícitamente coles señes culturales en víes de desapaición, incluyendo tanto la cultura material como les formes de rellación y la llingua asturiana.

Para Xuan Bello, Paniceiros constituye el centro de ese particular mundo al que pertenece, con el que se identifica y donde se encuentra con uno de sus tantos yoes que se aúnan en su múltiple identidad. El autor refleja la visión de un Paniceiros en el que en días pasados habitaba una comunidad que creía en la prosperidad, un colectivo ${ }^{\text {Io }}$ del que el autor también forma parte. Hoy, ese lugar mitificado solo pervive en la memoria de aquellos que lucharon por levantar ese mundo que ahora está sepultado bajo las ruinas del olvido. Ahora es un lugar abandonado que ve cómo se difuminan sus señas de identidad cultural.

La autotraducción le concede al autor-traductor la posibilidad de redibujar el paisaje que ha proyectado en asturiano. A pesar de que autotraducirse puede entenderse como un sinónimo de reinventar el texto, observamos que Xuan Bello no introduce modificaciones en su poema traducido al español. Deducimos entonces, que la intención de este poeta no es utilizar la autotraducción para mejorar el poema, sino para reconstruir la imagen de su Paniceiros natal en el otro sistema -donde quizás se desconoce su existencia- jugando con los recursos del español, su otra len-

ro En el poema Paniceiros, Xuan Bello trata de aunar la voz del pueblo, por lo que recurre a la primera persona del plural. Así, se expresa mediante un «nosotros» y, además, hace referencia a lo «nuestro». 
gua. Tras esta imagen retratada con palabras, se esconde un mensaje de reivindicación de la identidad cultural de Asturias, impregnado de esas notas melancólicas, característico de la poesía de los escritores del Surdimientu.

En el texto traducido, Xuan Bello traslada la imagen de aquellos elementos materiales y, a su vez, socioculturales que constituyen algunas señas de identidad del pueblo asturiano como, por ejemplo, el hórreo, el molino, la iglesia, la casa y los demás elementos relacionados con la naturaleza. Todos estos recrean la idílica vida en el campo, allí donde se hunden los orígenes de una región tradicionalmente campesina que siempre ha estado unida a la tierra, a la naturaleza, a unas costumbres y a la lengua asturiana. Se resalta ese «sentimiento de la tierra» a través del que se manifiesta el lamento compartido de una comunidad por el abandono de la arcaica - pero armónica-, vida rural, totalmente opuesta a la ciudad, aquel lugar al que los asturianos se exilian. Ese «sentimiento de la tierra» también se relaciona con la derrota por haber permitido que las tradiciones de Asturias cayeran en el olvido.

La autotraducción permite extender la reivindicación sociocultural que Xuan Bello dirige, concretamente, a la comunidad asturiana a través de poemas como Paniceiros. De esta manera, pretende despertar en todos los asturianos ese deseo por rescatar la esencia de su cultura y por reafirmar su postergada identidad colectiva.

Además, al autotraducirse a su otra lengua, el poeta consigue que sus reivindicaciones traspasen las fronteras del Principado de Asturias, de manera que se escucharán en otros territorios. Así, se espera que el texto traducido al español llegue a las manos del mayor número de lectores posibles que proceden de sociedades diferentes que configuran el diverso y «plurinacional» mapa de España. Al estar insertos en otros subsistemas peninsulares, consideramos que es bastante improbable que estos individuos se interesen en participar activamente en la lucha por revivir las señas de identidad asturianas. No obstante, gracias a la autotraducción, 
conocerán que en Asturias existe este movimiento de reivindicación, e incluso pueden llegar comprender esta causa que algunos aún defienden.

\section{El poema «Narratio populi»}

La búsqueda de la identidad individual se refleja en numerosos poemas en los que Xuan Bello habla abiertamente sobre él mismo, su apreciación del mundo que le rodea y las vivencias personales que guarda en su memoria.

En el poema Narratio populi (I999, págs. 56-59), Xuan Bello refleja su pretensión por encontrarse con su todavía indefinida identidad. Las palabras que dan vida a los versos de Narratio populi dicen así:

\section{Narratio populi}

Ello ye me llamaba Juanjo.

$Y$ que tola mio infancia foi

una feliz sucesión de cases,

paisaxes, acentos que diben

de boca en besu,

mañanes fríes en trenes llargos

camin de la escuela.

También remembro

un país con árboles y ñeros

de zarrica, carros tiraos

polos últimos bueis del sol,

$y$ de súpeto yera agostu

cuando nes altes rames

del meudia

$$
\text { - engaramada- }
$$

la imaxe de lo que diba ser

mio vida y nun foi

(nun pudo ser)

madurecía sóleda, serena,

imposible.

\section{Narratio populi}

Resulta que yo me llamaba Juanjo.

$Y$ que toda mi infancia fue una feliz sucesión de casas, paisajes, acentos que iban de boca a beso, mañanas frías en trenes largos camino de la escuela.

También recuerdo un país con árboles y nidos de zorzal, carros tirados por los últimos bueyes del sol, $\mathrm{y}$ de pronto era agosto cuando en las altas ramas del mediodía

$$
\text { -encaramada- }
$$

la imagen de lo que sería mi vida y no fue (no pudo ser) maduraba solitaria, serena, imposible. 


\author{
Too ello dígolo \\ pa esplicar \\ (anque namás sía lateralmente) \\ el que güei escriba estos versos \\ otru que yo nun yera. Otru \\ que siempre vei conmigo: \\ esa sombra, Xuan Bello. \\ Pero ello ye llargo y posible- \\ mente ye yá otra historia. \\ Como'l que diz \\ granu d'otra sementera.
}

\author{
Todo esto lo digo \\ para explicar \\ (aunque sólo sea lateralmente) \\ que hoy escriba estos versos \\ otro que yo no era. Otro \\ que siempre va conmigo: \\ esa sombra, Xuan Bello. \\ Pero esto es largo y posible- \\ mente es ya otra historia. \\ Como quien dice \\ harina de otro costal.
}

En este poema, Xuan Bello evoca los recuerdos de un tiempo pasado irrepetible: la infancia. El poeta rescata de su memoria las imágenes de una etapa feliz que vivió en ese territorio idílico donde uno podía sentir el abrazo de la naturaleza, el calor de la casa, y también escuchar la melodía de una lengua que ha ido perdiendo su fuerza. Un lugar donde podría haber vivido aquella vida que siempre deseó tener. Ese territorio es esa patria de la que fue exiliado, la cual pretende reconstruir no solo mediante sus composiciones en asturiano, sino también mediante las traducciones que realiza al español. De esta manera, otros lectores insertos en el variado sistema peninsular podrán conocer que una vez existió un lugar que representaba un símbolo de identificación asturiana. Hoy en día, esa patria ha quedado reducida a ruinas y todavía busca renacer. Por un lado, esta patria puede relacionarse con Paniceiros, ese territorio que Xuan Bello describe como el centro del mundo, aquel paraíso perdido que representa «ese sentimiento tan asturiano de añoranza, no solo de lo vivido, sino también de lo que nunca fue, pero pudo haber sido» (Prieto, 2004, pág. 4). Por otro lado, esa patria puede vincularse con las señas de identidad asturianas, como son las tradiciones o los elementos materiales propios de su cultura. O incluso la esencia de esa patria puede residir en 
la lengua autóctona, pues como bien apunta Ramis (2013, pág. 6), «cada lengua es una patria diferente».

A través del poema autotraducido, el poeta no solo trata de recrear la imagen de esa patria, sino también de ahondar en esa sensación de vacío que reside en su interior desde que abandonó ese territorio donde se hallan sus orígenes. Sin embargo, ese exilio no debe entenderse como un desplazamiento únicamente físico, puesto que también alude a un extrañamiento tanto existencial como cultural (Mori, 2006, pág. I5). Un extrañamiento que desemboca en un sentimiento de nostalgia hacia la vida en el campo en la que se hunden las raíces de esa lengua y cultura de origen asturiano. De esta manera, deducimos que Xuan Bello experimenta lo que se conoce como el exilio interior. Se trata pues, de una emoción que comparten aquellos poetas asturianos que luchan por reconstruir la identidad cultural de Asturias, al mismo tiempo que intentan definir la suya propia, como sujetos individuales que son. Así, la autotraducción puede contemplarse como un medio que arroja luz a ese sendero que finaliza allá donde uno se funde en el encuentro consigo mismo.

En el poema Narratio populi escrito en asturiano, Xuan Bello reflexiona sobre su propia identidad. Por tanto, reflexiona sobre quién fue, sobre los recuerdos que alimentaron su persona y, en definitiva, se cuestiona quién es realmente en ese tiempo que considera presente. Sin embargo, el poeta decide salir del espacio limitado por esta lengua minoritaria y se aventura a emprender el camino de la «autobúsqueda» a través de otra lengua que conoce de cerca, de manera que recurre a la autotraducción.

A pesar de observarse desde dos perspectivas diferentes -al escribir en dos lenguas-, el autor-traductor continúa retratándose como un individuo desubicado, incluso casi desconocido. Tanto en su texto compuesto en asturiano y en el traducido al español explica que, en el pasado, fue un joven con otro nombre, o sea, una persona diferente a la que es en 
este tiempo presente. Ahora es otro, aunque es un "otro» que todavía no ha conseguido definir. No obstante, en el texto que autotraduce reafirma que a este «otro" -ese ser que trata de identificar- siempre le acompaña «una sombra» que se hace llamar Xuan Bello que quizás puede ser esa esencia que comparten las distintas identidades. De esta manera, interpretamos que ese "otro» es un individuo que en su interior aúna múltiples identidades que él mismo aún tiene que ir descubriendo a través de una poesía escrita tanto en asturiano como en español. Poemas que hilan una historia sobre la búsqueda de las señas culturales asturianas y la identidad individual. Una historia cuyo final, por ahora, está aún por escribir.

\section{Conclusiones}

Existen autores bilingües y biculturales insertos en el sistema peninsular que se sirven de la autotraducción para hacer visible la existencia de su lengua y su cultura minoritarias y proyectarlas hacia sistemas mayoritarios. De esta manera, mediante sus traducciones, tratan de cumplir con los compromisos que mantiene con su comunidad que busca consolidar su identidad cultural y lingüística.

Respecto al caso específico de Xuan Bello, podemos concluir que, tras haber traducido sus propias obras al español, ha logrado cumplir con un objetivo primordial: difundir sus poemas en el sistema peninsular. Por consiguiente, los mensajes reivindicativos que recorren sus versos han llegado a manos de otros lectores que no pertenecen al subsistema asturiano. De esta manera, consideramos que la autotraducción se convierte en un instrumento significativo para el movimiento de defensa de la cultura, lengua y literatura asturianas, conocido como Surdimientu, en la que encuentra un apoyo importante. Así, estimamos que la autotraducción contribuye a extender las demandas culturales y lingüísticas de aquellos comprometidos con la protección y difusión del asturiano. Al mismo tiempo, el hecho 
de autotraducirse permite a los poetas asturianos, que participan en este movimiento reivindicativo desde la literatura y la traducción, conservar su voz y proyectar sus perspectivas en el sistema central.

$\mathrm{Al}$ ser su propio traductor, Xuan Bello se esfuerza por transmitir en su otra lengua un mensaje con una importante carga cultural. A través de la traducción, el autor contribuye a fortalecer la imagen de Asturias y a recordar que el tiempo y el olvido todavía no han sido lo suficientemente fuertes como para silenciar la voz de la lengua asturiana. En sus poemas en asturiano y español, Xuan Bello también trata de recuperar las señas autóctonas que caracterizan su comunidad con el fin de reafirmar la identidad de la cultura asturiana, periférica dentro del complejo sistema peninsular. En suma, se trata de una identidad que pretende alzarse como el punto de encuentro de todos los asturianos. Aunque cabe apuntar que Xuan Bello no solo se traduce a sí mismo para reconstruir exclusivamente la identidad colectiva de Asturias, sino también para perseguir otro fin. En definitiva, lo que también anhela es encontrar su propia identidad individual.

Autotraducirse puede entenderse también como un sinónimo de autodefinirse. El poeta asturiano halla en la traducción de sí mismo una oportunidad para "reescribirse», es decir, para volver a reflejar sus reflexiones de carácter existencialista en su otra lengua, de manera que se puede ver desde otra perspectiva. Xuan Bello no se limita simplemente a trasladar las palabras que componen sus poemas, pues cuando se autotraduce, vuelve a pensar sobre la imagen de él mismo como un individuo que aúna en sí múltiples identidades y que se sitúa en un espacio intermedio entre dos sistemas socioculturales a los que, a su manera, siente que pertenece. Un individuo con una faceta bilingüe y bicultural que, a través de su poesía, intenta trazar el camino que le guíe hacia el (re)descubrimiento de su identidad, un camino que puede tomar en dos direcciones: en asturiano o en español. 
La autotraducción, por tanto, se puede ver como un medio que ayuda a Xuan Bello en su búsqueda hacia la definición de su propia identidad. No obstante, únicamente mediante la observación de sus poemas autotraducidos, no podemos comprobar con total certeza si Xuan Bello consigue determinar su identidad. La última palabra que puede dar respuesta a estas cuestiones que pretenden indagar en la construcción de su identidad la tiene, sin duda alguna, el poeta asturiano.

\section{REFERENCIAS BIBLIOGRÁFICAS}

Bello (1999) = Xuan Bello, La vida perdida, Xixón (Libros del Pexe), 1999.

Carbonell (1997) = Ovidi Carbonell i Cortés, Traducir al otro: traducción, exotismo, poscolonialismo, Cuenca (Ediciones de la Universidad de Castilla-La Mancha), 1997.

Castillo (2006) = Gema S. Castillo García, la (auto)traducción como mediación entre culturas, Alcalá de Henares (Universidad de Alcalá de Henares), 2006.

Cocco (2009) = Simona Cocco, «Lost in (Self-) Translation? Riflessione sull'autotraduzione», AnnalSS. Lost in Translation. Testi e culture allo specchio, 6 (2009), págs. I03-II8. [En línea: <http://hostweb3.ammin.uniss.it/lingue/annali_file/vol_6/8_Cocco_Lost.pdf>, consulta: 07-06-20I7].

Dasilva (2OI5) = XosÉ M. DAsILVA, «La opacidad de la autotraducción entre lenguas asimétricas», Revista Trans 19, vol. II (2015), págs. I7I-I82. [En línea: <http://www. trans.uma.es/Trans_I9-2/Transi92_AIw.pdf>; consulta: 06-06-20I7].

García del Villar (2005) = Reyes García del Villar Balón, "Los métodos de la antropología y la literatura", en Revista de Dialectología y Tradiciones Populares vol. LX/I (2005), págs. 43-58. [En línea: <http://rdtp.revistas.csic.es/index.php/rdtp/article/ viewFile/II4/II5>; consulta: 07-06-2017].

Ghignoli \& Hernández Rodríguez (20i5) = Alessandro Ghignoli \& EstefaNíA HeRnÁndez RodrígueZ, «La autotraducción literaria. Una escritura poscolonial», en Daniele Corsi y Julio Pérez-Ugena (eds.), Mosaico. La traduzione letteraria, Arezzo (Bibliotheca Aretina), 2015.

Grutman (2OI2) = Rainier Grutman, "L'autotraduzione verticale ieri e oggi (con esempi dalla Spagna cinquecentesca e novecentesca)», en M. Rubio Árquez \& N. 
d'Antuono (eds.), Autotraduzione. Teoria ed esempi fra Italia e Spagna (e oltre), Milano (Edizioni Universitarie di Lettere Economia Diritto), 20I2, págs. 33-48.

Hernández (20IO) = Belén Hernández, «El fenómeno cotidiano de la «autotraducción» en Italia y España», Estudios Románicos, I9 (2010), págs. II3-I26. [En línea: <https://digitum.um.es/xmlui/bitstream/IO2OI/27930/I/II655I-462I6I-I-PB.pdf>; consulta: 06-06-2017].

MORI (2006) = MARTA MORI DE ARRIBA, «L'exiliu interior: el sentimientu de la tierra na poesía asturiana contemporánea», Lletres Asturianes 93 (2006), págs. 15-27. [En línea: $<$ http://www.academiadelallingua.com/lletresasturianes/pdf/Art\% $\mathrm{C}_{3} \% \mathrm{ADculu} \% 20$ 2-Marta\%2oMori\%2od\%C2\%B4Arriba-L\%C2\%B4exiliu\%2ointerior.\%2oel\%2o sentimientu\%2ode\%2ola\%2otierra\%2ona\%2opoes\%C3\%ADa\%2oasturiana\%2ocontempor\%C3\%Ainea.pdf>; consulta: 06-06-20I7].

Nowicki $(2007)$ = JOANNA NowICKI, «Les enjeux identitaires de la traduction: les écrivains de l'autre Europe», Hermès, 49 (2007), págs. I69-174. [En línea: <http:// documents.irevues.inist.fr/bitstream/handle/2042/24I4I/HERMES_2007_49_169. pdf?sequence $=\mathrm{I} \&$ isAllowed $=\mathrm{y}>$; consulta: $06-06-2017]$.

Popovič (1976) = ANTON Popovič, Dictionary for the analysis of literary translation, Edmonton (Department of Comparative Literature: The University of Alberta), 1976.

Prieto (2004) = Esther Prieto Alonso, «Poesía actual en Asturias: de la pérdida a la reacomodación", en XX Encuentro en Verines. Bajo el signo de la pluralidad: la poesía actual, Casona de Verines, Pendueles (Asturias), 2004. [En línea: <http://www.mecd. gob.es/lectura/pdf/Vo4_PRIETO.pdf>; consulta: 06-06-20I7].

RAmis (2013) = Josep M. RAmIs, «La autotraducción y el difícil encaje de sistemas literarios en contacto", EU-topias, 5 (2013), págs. I-I7. [En línea: <http://eu-topias.org/ la-autotraduccion-y-el-dificil-encaje-de-sistemas-literarios-en-contacto/>; consulta: o607-2017].

Revista Biblioasturias (20II) = "Xuan Bello. Soy de Paniceiros: soy del mundo» (entrevista), Biblioasturias. Revista de las bibliotecas públicas del Principado de Asturias, I9 (20II), págs. 22-26, Oviedo (Consejería de Cultura y Turismo. Viceconserjería de Promoción Cultural y Política Lingüística). [En línea: <https://www.asturias.es/Asturias/descargas/PDF_TEMAS/REVISTA\%20BIBLIOASTURIAS/biblioasturiasi9. pdf>; consulta: 06-06-2017].

SANtori (2OI3) = Xuan SANTori Vázquez-Azpiri, El Surdimientu y la lliteratura n'asturianu: normalización y estandarización, Uviéu (Trabe), 2013.

Santoyo (20I5) = Julio C. SANToyo, "Consideraciones acerca del estatus actual de la autotraducción en la Península Ibérica», en Glottopol, 25 (20I5), págs. 47-58. [En 
línea: <http://glottopol.univ-rouen.fr/telecharger/numero_25/gpl25_03santoyo.pdf>; consulta: 06-07-2017].

TANQUeIro (1999) = Helena TANQueIro, «Un traductor privilegiado: el autotraductor», en Quaderns. Revista de traducció, 3 (1999), págs. I9-27. [En línea: <https:// ddd.uab.cat/pub/quaderns/I1385790n3/I1385790n3pı9.pdf>; consulta: 07-06-2017].

VeGA (2002) = Regina VeGA, "Un jardinero en la frontera. Las autotraducciones de Álvaro Cunqueiro", en Quimera, 210 (2002), págs. 46-50. [En línea: <http:// www.academia.edu/I0520582/Un_jardinero_en_la_frontera._Las_autotraducciones_ de_\%C3\%8Ilvaro_Cunqueiro>; consulta: 06-06-20I7]. 

